\title{
Circadian gastric acidity in Helicobacter pylori positive ulcer patients with and without gastric metaplasia in the duodenum
}

\author{
V Savarino, G S Mela, P Zentilin, M R Mele, L Lapertosa, R Patetta, E Dallorto, \\ A Vassallo, C Mansi, S Vigneri, G Celle
}

\begin{abstract}
Background-The presence of gastric metaplasia allows Helicobacter pylori to colonise the duodenum and this condition is thought to be acquired as a response to acid hypersecretion. This functional disorder, however, is present only in a subgroup of duodenal ulcer patients and, in addition, surface gastric metaplasia has been frequently found in the proximal duodenum of normal subjects and patients with non-ulcer dyspepsia, who cannot be certainly considered as acid hypersecretors.
\end{abstract}

Aims-To clarify the role of acid in inducing gastric type epithelium in the duodenum. This study aimed at assessing whether the pattern of circadian gastric acidity differs between $H$ pylori positive duodenal ulcer patients with and without duodenal gastric metaplasia.

Patients-Seventy one patients with duodenal ulcer confirmed by endoscopy and who were found to be positive for $H$ pylori infection by histology on antrum biopsy specimens were enrolled into this study. Methods-Gastric type epithelium in the duodenum was found in 49 of 71 ulcer patients $(69 \%)$. Continuous 24 hour gastric pH metry was performed in $\mathbf{5 0}$ healthy subjects and in the two subgroups of duodenal ulcer patients with and without gastric metaplasia in the duodenum. Gastric acidity was calculated for 24 hours (1700-1659), night (2000-0759) and daytime (0800-1959).

Results-Ulcer patients without gastric metaplasia showed a significantly higher gastric acidity $(p<0.001)$ than controls for every time interval considered, while the ulcer subgroup with gastric metaplasia was more acid than healthy subjects $(p<0.001)$ during the whole 24 hour period and the daytime. There was no difference between the two subgroups of duodenal ulcer patients with and without gastric metaplasia during the various time segments analysed.

Conclusions-The findings confirm that the circadian gastric acidity of duodenal ulcer patients is higher than that of controls. As there is no difference in gastric pH between duodenal ulcer patients with and without gastric metaplasia, gastric hyperacidity is not specific to patients with duodenal gastric metaplasia. It is probable that this histological change is a non-specific response to mucosal injury resulting from various factors and not exclusively to acid.

(Gut 1996; 39: 508-512)

Keywords: duodenal gastric metaplasia, duodenal ulcer, gastric acidity, Helicobacter pylori, $\mathrm{pH}$ monitoring.

It is now generally accepted that Helicobacter pylori infection causes type $\mathrm{B}$ chronic gastritis and is frequently associated with peptic ulceration. ${ }^{1}$ The pathogenetic link between $H$ pylori and duodenal ulcer, however, is still not clear. As the germ colonises only gastric type epithelium, many authors ${ }^{2-4}$ have hypothesised that it contributes to ulceration by growing on areas of gastric metaplasia in the duodenum. When these areas are infected, chronic duodenitis develops and then duodenal ulcer may occur. $^{5}$

The development of duodenal gastric metaplasia is believed to be a protective mechanism secondary to acid injury. ${ }^{6}$ The responsibility of acid in this process seems to be supported by experimental ${ }^{78}$ and human studies. ${ }^{9-12}$ However, this evidence is countered by the following findings. Epithelium with gastric metaplasia has been found in up to $22 \%-64 \%$ of normal subjects, ${ }^{13}{ }^{14}$ who cannot be defined as acid hypersecretors. In addition, patients with duodenal ulcer certainly represent a population secreting, on average, more acid than normal, ${ }^{15}$ but it is well known that only one third of these patients have peak acid output above the upper limit of normal. ${ }^{16}$ Although a rapid gastric emptying may also produce an increased acid load to the duodenum with subsequent possible mucosal injury, only a subgroup of duodenal ulcer patients shows this functional disorder. ${ }^{17}$ Finally, duodenal gastric metaplasia has been found in a high proportion of patients with non-ulcer dyspepsia, ${ }^{6}{ }^{11}{ }^{18}$ who have a basal acid output comparable to that of normal subjects ${ }^{19}$ and a circadian gastric acidity significantly lower than normal. ${ }^{20}$ Apart from data obtained in animal studies, the 
number of papers that correlated directly gastric acid with duodenal gastric metaplasia in human beings are few. ${ }^{11}{ }^{121}$ More importantly, the evaluation of gastric acidity in these studies is highly questionable, because $\mathrm{pH}$ was measured in single samples of gastric juice collected during unphysiological endoscopy. For instance, some authors ${ }^{11}$ chose $\mathrm{pH} 2.5$ as the threshold below which gastric juice was considered consistently acid and this allowed them to correlate the presence of high acidity with gastric metaplasia. It should be remembered, however, that a $\mathrm{pH}$ value of 2.5 units is poorly representative of the low $\mathrm{pH}$ values commonly found in basal gastric juice of both normal subjects and duodenal ulcer patients. ${ }^{22}{ }^{23}$ The physiological recording of gastric $\mathrm{pH}$ is now possible by means of modern computerised devices that allow us to describe accurately all the time related acidity variations within the stomach over the circadian cycle. ${ }^{24}$

As the relation between gastric acid and the formation of duodenal gastric metaplasia is still controversial, we carried out this study to assess whether the pattern of circadian gastric acidity differs between $H$ pylori positive duodenal ulcer patients with and without gastric metaplasia in the duodenum.

\section{Methods}

\section{Patients}

Seventy one patients with duodenal ulcer confirmed by endoscopy and found to be $H$ pylor positive were enrolled into this study. Patients receiving non-steroidal anti-inflammatory drugs or longterm treatment with powerful antisecretory drugs were excluded. $H$ pylori infection was verified by histology on two biopsy specimens taken from the antrum, fixed in formalin, and stained with the well established Warthin-Starry and modified Giemsa methods. Two additional biopsy specimens were taken from the duodenum at the margins of the ulcer crater to detect areas of gastric metaplasia, which have been shown frequently in this site. ${ }^{25}$

Gastric metaplasia was defined as the occurrence of foci of gastric epithelial cells containing apical PAS positive neutral mucine together with the absence of a brush border. Forty nine patients $(69 \%)$ were found to have surface gastric metaplasia (31 male, mean (SD) age $47(12))$ and 22 patients (31\%) were found to be devoid of gastric metaplasia in the duodenum (14 male, mean (SD) age 44 (15)). There was no significant difference between the two subgroups with and without gastric metaplasia with regard to ulcer size $(12 \cdot 1(2 \cdot 6)$ $\mathrm{mm} v 10.9(2 \cdot 2))$, length of history $(10.8(9 \cdot 9)$ years $v 11.3(12.2)$, and number of ulcer relapses $(8.8(9.7) v 7.6(7 \cdot 8))$. All patients gave their informed consent to the study, which was also approved by the local ethical committee.

pH Monitoring

All duodenal ulcer patients underwent 24 hour continuous gastric $\mathrm{pH}$ metry within three days of the endoscopic diagnosis of the ulcer niche. During this interval they were asked to take only antacids for symptom control, if necessary, and these drugs were withdrawn the day of examination. No patient was being treated with antisecretory drugs during the two weeks preceding the test or had undergone previous gastric surgery. The examination was performed with two closely adjacent $\mathrm{pH}$ electrodes that were positioned about $10 \mathrm{~cm}$ below the cardia, using a well established procedure. ${ }^{26} 27$ This method removes noise, interference, and artefacts superimposed to the endoluminal $\mathrm{pH}$ tracings, thus improving the accuracy of 24 hour pH metry in every clinical condition. The 24 hour mean $\mathrm{pH}$ profile obtained in each patient by averaging the $\mathrm{pH}$ tracings of the two channels every minute is calculated for final analysis. Obviously, tracings where $\mathrm{pH}$ readings vary for more than one hour over 24 hours cannot be considered valid and were repeated. ${ }^{27}$ The test was also performed in 50 healthy subjects ( 30 male, mean (SD) age $47(10)$ ) who were asymptomatic and had no history of relevant gastroenterological or systemic disease and were used as controls. The search for $H$ pylori infection was not performed in them, but it has been shown that there is no difference in 24 hour gastric acidity between $H$ pylori positive and negative normal subjects ${ }^{28}$ and chronic $H$ pylori infection does not change the circadian pattern of gastric acidity. ${ }^{22} 29$ In total, four tests had to be repeated because of discrepancies lasting for more than one hour over the entire circadian cycle between the two simultaneous tracings of each examination. Patients and controls were fully ambulatory and smoking was permitted, because it has been shown not to affect the gastric $\mathrm{pH}$ pattern. ${ }^{30}$ During the test day, the time of the meals (dinner at 1800 , breakfast at 0800 , and lunch at noon), and composition ${ }^{31}$ were standardised. Extra food or water or alcoholic and carbonated beverages were forbidden.

\section{Data processing and statistical analysis}

At the end of each run, experimental data were downloaded into a calculator (Compaq, Proliant) using service routines. The $\mathrm{pH}$ readings of the two channel tracings of each patient were averaged every minute, ${ }^{27}$ so that 1440 datapoints/24 hours were obtained. Acidity data were expressed as mean pH (SD) values $^{31}{ }^{32}$ for three different time intervals: 24 hours; night (2000-0759) and daytime (0800-1959). These findings were compared by means of two way ANOVA and $p$ values were corrected for multiple testing. The density distribution of 24 hour $\mathrm{pH}$ values were also calculated for each population. Patient characteristics were compared by means of Student's $t$ test. Statistical significance was set at $\mathrm{p}<0 \cdot 05$.

\section{Results}

Figure 1 shows the 24 hour mean $\mathrm{pH}$ profiles obtained in normal subjects and in duodenal 


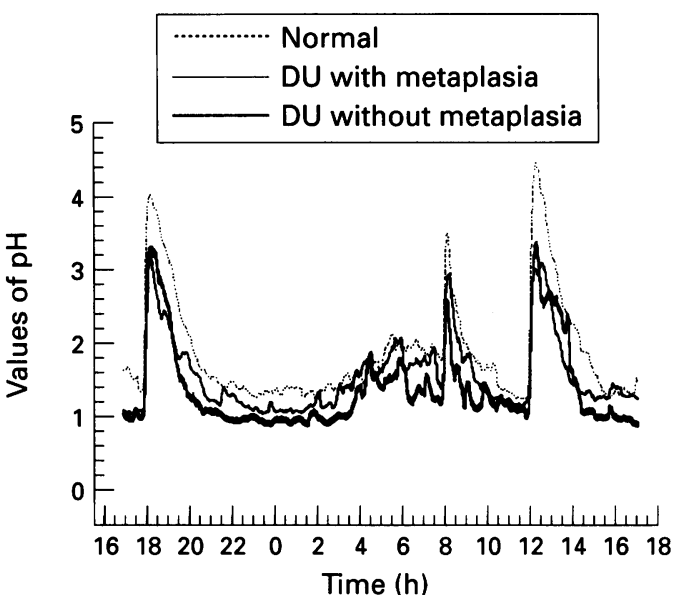

Figure 1: 24 Hour mean $\mathrm{pH}$ profiles of the three populations studied. Meals were given at 1800,0800, and 1200.

ulcer patients with and without gastric metaplasia. The curves pertaining to the two subgroups of duodenal ulcer patients are rather superimposed and run below that of controls during almost the whole 24 hour period. The difference between ulcer patients and normal subjects is particularly evident during the first half of the night and the postprandial periods.

The Table shows the mean $\mathrm{pH}$ values of each population calculated for three different time intervals. The two subgroups of $H$ pylori positive duodenal ulcer patients have significantly higher acidity than normal subjects $(p<0.001)$ during the whole 24 hour period and the daytime. Patients without gastric metaplasia maintain higher acidity than normal also during the night $(p<0.001)$, while those with gastric metaplasia do not differ from controls in this period. On the other hand, the acidity patterns of the two subgroups of duodenal ulcer patients with and without gastric metaplasia do not differ for every time segment considered.

The analysis of the density distribution of 24 hour $\mathrm{pH}$ values (Fig 2) shows that the peaks at the lowest $\mathrm{pH}$ values, denoting the highest acidity, are much more evident for the two subgroups of duodenal ulcer patients than for normal subjects.

\section{Discussion}

Our study shows that ulcer patients with and without gastric metaplasia in the duodenum have a similar pattern of gastric acidity and both subgroups are significantly more acid than normal subjects over the 24 hour period. The existence of higher acidity in patients with duodenal ulcer than in healthy subjects is a well established finding in pathophysiological

Mean $p H$ values (SD) during three different time intervals for each population

\begin{tabular}{llll}
\hline Time period & $\begin{array}{l}\text { Normal } \\
\text { subjects }\end{array}$ & $\begin{array}{l}\text { Duodenal ulcer } \\
\text { with metaplasia }\end{array}$ & $\begin{array}{l}\text { Duodenal ulcer } \\
\text { without metaplasia }\end{array}$ \\
\hline $1700-1659$ & $1 \cdot 9(0 \cdot 4)$ & $1 \cdot 6(0 \cdot 5)$ & $1 \cdot 4(0 \cdot 4)$ \\
$2000-0759$ & $1 \cdot 6(0 \cdot 5)$ & $1.4(0 \cdot 6)$ & $1 \cdot 2(0 \cdot 3)$ \\
$0800-1959$ & $2 \cdot 2(0 \cdot 5)$ & $1 \cdot 8(0 \cdot 5)$ & $1 \cdot 7(0 \cdot 5)$ \\
\hline
\end{tabular}



Figure 2: Density distributions of $p H$ values over the whole 24 hour period for the three populations that were analysed.

studies with continuous longterm $\mathrm{pH}$ monitoring. ${ }^{22}{ }^{23}$ On the other hand, the similar pattern of gastric acidity in $H$ pylori positive ulcer patients with and without duodenal gastric metaplasia casts some doubts about the responsibility of acid in inducing the development of gastric type epithelium in the duodenum of these patients. Using traditional acid secretory tests, Patrick ${ }^{33}$ also observed the lack of correlation between gastric hyperacidity and duodenal gastric metaplasia, while Kreuning ${ }^{34}$ found that superficial gastric metaplasia in the duodenum was directly correlated to gastric acid secretion. Our technique measuring gastric $\mathrm{pH}$ over the entire circadian cycle provides us with information on both fasting and meal related gastric acidity and it is certainly more accurate than that achievable by only assessing the $\mathrm{pH}$ of a single gastric juice sample collected during an unphysiological manoeuvre, such as endoscopy. ${ }^{11} 1221$ It is probable that the direct correlation of acid with the extent of gastric type epithelium in the duodenum is the best way to define its role in inducing this histological change. If acid is the most important factor, it is to be expected that it increases in parallel with the degree of gastric metaplasia. We have recently evaluated this relation in $47 \mathrm{H}$ pylori positive duodenal ulcer patients, in whom gastric metaplasia was graded by assessing four biopsy specimens from the duodenal bulb (personal unpublished observations). We found that there is a progressive, although not significant, reduction of 24 hour gastric acidity as the extent of gastric metaplasia increases: $\mathrm{pH} 1.4(0.4) v$ gastric metaplasia $<5 \%(\mathrm{n}=19) ; \mathrm{pH} 1.6(0.4) v$ gastric metaplasia 5-20\% (n=14); $\mathrm{pH} 1.7(0.3) v$ 20-50\% (n=8); pH 2.0 (0.5) $v$ gastric metaplasia $>50 \%(n=6)$. These findings seem to confirm further that acid cannot be considered the only factor implicated in the formation of duodenal gastric metaplasia.

Using two biopsy specimens from the duodenum, we found gastric metaplasia in $69 \%$ of our $H$ pylori positive ulcer patients. This proportion is in keeping with average data published in medical literature on this type of patient and ranging from $39 \%$ to $92 \%{ }^{6}$ It is noteworthy that even a single biopsy specimen taken from the edge of a consecutive series of duodenal ulcers allowed some authors to show 
the presence of gastric metaplasia in $92 \%$ of cases. $^{25}$ More recently, however, a large number of duodenal biopsy specimens has been recommended to improve the detection of gastric metaplasia, ${ }^{12}$ which is generally patchily distributed. Yang ${ }^{35}$ found duodenal gastric metaplasia in $83 \%$ of Chinese duodenal ulcer patients by examining four biopsy specimens taken from the ulcer margins. In the light of this study, we may have missed some patients with gastric metaplasia because of the small number of biopsy specimens, but, if so, we think that the reflections on the overall results of our study should only be marginal. Our experimental findings, in fact, show a clear tendency towards higher acidity in ulcer patients without duodenal gastric metaplasia compared with those who have gastric metaplasia and therefore moving some of the patients from the first group to the second group would only result in a major equivalence between them.

If gastric hyperacidity is not specific to patients with duodenal gastric metaplasia compared with those without this histological alteration, an augmented load of acid to the duodenum may be proposed as alternative cause of this type of injury. We have already emphasised that an accelerated gastric emptying is only characteristic of a subgroup of duodenal ulcer patients ${ }^{17}$ and, therefore, other mechanisms may be involved, such as a defective buffering of duodenal acid on the part of bicarbonates secreted by the pancreas or duodenal mucosa. A reduced secretion of pancreatic bicarbonates has been already described in duodenal ulcer, ${ }^{36}$ but the impairment of duodenal bicarbonates should also be taken into account. In another study, Rapier ${ }^{37}$ showed that $H$ pylori diminishes proximal duodenal mucosal bicarbonate secretion in patients with duodenal ulcer and, more importantly, this reduction returns to normal after $H$ pylori is eradicated. It is also true, however, that the important role of the neutralisation process of acid within the duodenal bulb has been highly questioned in another study. ${ }^{38}$ These authors measured simultaneously gastric and duodenal $\mathrm{pH}$ and showed that bulb acidity does not significantly differ between healthy subjects and patients with duodenal ulcer. Moreover, there was no difference between normosecretor controls and hypersecretor ulcer patients and this seems to further exclude the pathogenetic relevance of acid in causing increased duodenal aggression. An additional study on the pattern of intraduodenal acidity ${ }^{39}$ confirmed that bulb $\mathrm{pH}$ is similar in patients with active ulceration and controls, even though a higher bulb acidification can be seen in patients with healed ulcers. Further support for an incomplete correlation between excess secretion of acid and duodenal gastric metaplasia comes from the finding that the extent of gastric type epithelium is not affected by the longterm use of powerful antisecretory drugs, such as $\mathrm{H}_{2}$ receptor antagonists, ${ }^{64041}$ and from the conflicting results on its reversal after parietal cell vagotomy. ${ }^{40} 42$ It has been preliminarily seen, however, that the more profound acid inhibition achievable with the proton pump inhibitor omeprazole may favour the regression of gastric metaplasia, ${ }^{6}$ but this must be confirmed in an appropriate number of patients. In our opinion, an important elucidation of the role of acid in inducing gastric metaplasia in the duodenum would also come from the assessment of the prevelance of duodenal gastric type epithelium in patients with chronic atrophic gastritis and complete impairment of acid secretion.

It is also unclear whether the development of duodenal gastric metaplasia is a reaction to inflammation or a primary phenomenon. Fitzgibbons $^{13}$ found that gastric metaplasia often occurs in the distal duodenal bulb of normal subjects in the absence of severe duodenal inflammation and Noach $e t a l^{6}$ excluded any significant change in duodenal gastric metaplasia one year after $H$ pylori eradication and the probable improvement of the organism related inflammatory process. More recently, however, Khulusi ${ }^{41}$ showed that the extent of gastric metaplasia in duodenum declines 10 months, on average, after $H$ pylori eradication. Thus, the bacterium itself and its related duodenal inflammation seems to be responsible for the formation or, at least, the further stimulation of gastric type epithelium in the duodenum. ${ }^{12}$ On the other hand, the role of chronic inflammation in inducing gastric metaplasia seems to be also confirmed by the detection of this histological abnormality in patients with chronic inflammatory disease, such as Crohn's disease at different sites in the gastrointestinal tract and intestinal tubercolosis. ${ }^{6434}$ It is also true that gastric metaplasia has been found in many areas of the gastrointestinal tract, including the rectum, pancreas, and gall bladder, ${ }^{3}$ where the contact of acid can be absolutely excluded and therefore this factor is not required for its development.

Further confirmation that factors other than acid can be implicated in the genesis of gastric metaplasia in the duodenum derives from two studies, ${ }^{18}{ }^{45}$ which have shown that heavy alcohol consumption is associated with the formation of duodenal gastric type epithelium. This finding and the above considerations seem to highlight the fact that gastric metaplasia is a non-specific response to mucosal injury and many factors can be responsible for this process, including acid and other substances or events.

In conclusion, our study shows that circadian intragastric acidity does not differ between $H$ pylori positive duodenal ulcer patients with and without gastric metaplasia in the duodenum. Thus, an increased gastric acidity cannot be considered an essential factor in the development of duodenal gastric metaplasia. As this can be considered a non-specific response to mucosal injury, it is probably associated with many factors and not exclusively to acid.

This study has been presented in part to the Digestive Disease Week, San Diego, USA, May 1995 and published in abstract form in Gastroenterology 1995; 108 (suppl): A211. 
1 Peterson WL. Helicobacter pylori and peptic ulcer disease. N Engl f Med 1991; 324: 1043-8.

2 Marshall BJ, McGechie DB, Rogers PA, Glancy RJ. Pyloric Campylobacter infection and gastroduodenal disease. Med F A ust 1985; 142: 439-44.

3 Carrick J, Lee A, Hazell S, Ralston M, Daskalopoulos G. Campylobacter pylori, duodenal ulcer, and gastric metaplasia: possible role of functional heterotopic tissue in ulcerogenesis. Gut 1989; 30: 790-7.

4 Dixon MF, Wyatt JI. Helicobacter pylori infection and duodenal ulcer. $B M F$ 1991; 302: 1535.

5 Caselli M, TrevisaniL, AleottiA, Bovolenta MR, StabelliniG. Gastric metaplasia in duodenal bulb and Campylobacterlike organisms in development or duodenal ulcer. Dig Dis Sci 1989; 34: 1374-8.

6 Noach LA, Rolf TM, Bosma NB, Schartz MP, Oosting J, Rauws EAJ, et al. Gatric metaplasia and Helicobacte pylori infection. Gut 1993; 34: 1510-4.

7 Rhodes J. Experimental production of gastric epithelium in the duodenum. Gut 1964; 5: 454-8.

8 Tatsuta M, Iishi H, Yamamura H, Yamamoto R, Taniguchi $H$. Enhancement of tetragastrin of experimental induction of gastric-epithelium in the duodenum. Gut 1989; 30: gastric-

9 James AH. Gastric epithelium in the duodenum. Gut 1964; 5: $285-94$.

10 Parrish JA, Rawlins DC. Intestinal mucosa in the ZollingerEllison syndrome. Gut 1965; 6: 286-9.

11 Wyatt JI, Rathbone BJ, Dixon MF, Heatley RV. Campylobacter pyloridis and acid induced gastric metaplasia in the pathogenesis of duodenitis. $\mathcal{F}$ Clin Pathol 1987; 40; 841-8.

12 Wyatt JI, Rathbone BJ, Sobala GM, Shallcross T, Heatley RV, Axon ATR, et al. Gastric epithelium in the duodenum: its association with Helicobacter pylori and inflammation. it Clin Pathol 1990; 43: 981-6.

13 Fitzgibbons PL, Dooley CP, Cohen H, Appleman MD Prevalence of gatric metaplasia, inflammation, and Campylobacter pylori in the duodenum of members of a normal population. Am f Clin Pathol 1988; 90: 711-4.

14 Kreuning J, Bosman FT, Kuiper G, Wal AM, Lindeman J. Gastric and duodenal mucosa in "healthy" individuals. An endoscopic and histopatologic study of 50 volunteers. f Clin Pathol 1978; 31: 69-77.

15 Baron JH. An assessment of the augmented histamine test in the diagnosis of peptic ulcer. Gut 1963; 4: 243-53.

16 Baron JH. The relationship between basal and maximal acid output in normal subjects and patients with duodenal ulcer. Clin Sci 1963; 24: 357-70.

17 Lam SK. Pathogenesis and pathophysiology of duodenal ulcer. Clin Gastroenterol 1984; 13: 447-72.

18 Shousha S, Barrison IG, El-Sayeed W, Khan S, Parkins RA A study of incidence and relationship of intestinal metaplasia of gastric antrum and gastric metaplasia of duoplasia of gastric antrum and gastric metaplasia of duodenum in patients

19 Collen MJ. Gastric analysis (basal acid output) in non-ulcer dyspepsia. Dig Dis Sci 1990; 35: 540-1.

20 Savarino V, Mela GS, Celle G, Vigneri S. Acid and gastric metaplasia in the duodenum. Gut 1994; 35: 1151-2.

21 Saita H, Murakami M, Yoo JK, Teramura S, Dekigai $H$, Takahashi Y, et al. Link between Helicobacter pyloriassociated gastritis and duodenal ulcer. Dig Dis Sci 1993; 38: 117-22.

22 Wagner S, Gladziwa U, Haruma K, Varrentrapp M, Gebel M. Effect of Helicobacter pylori infection on 24 hour intragastric acidity in patients with gastritis and duodenal gastric acidity in patients with
ulcer. Gut 1992; 33: 1024-8.

23 Savarino V, Mela GS, Zentilin P, Malesci A, Vigneri S, Sossai $\mathrm{P}$, et al. Circadian acidity pattern in prepyloric ulcers: a comparison with normal subjects and duodena ulcer patients. Scand $\mathcal{F}$ Gastroenterol 1993; 28: 772-6.

24 Fimmel CJ, Etienne A, Cilluffo T, V Ritter T, Gasser T, Rey JP, et al. Long-term ambulatory gastric $\mathrm{pH}$ monitoring: validation of a new method and effect of H2-antagonists. Gastroenterology 1985; 88: 1842-51. 25 Marshall BJ, Goodwin CS, Warren JR, Murray R, blind trial of duodenal ulcer relapse after eradication of Campylobacter pylori. Lancet 1988; ii: 1437-42.

26 Mela GS, Savarino V, Moretti M, Sumberaz A, Bonifacino G, Zentilin $\mathrm{P}$, et al. Antimony and glass $\mathrm{pH}$ electrodes can be used interchangeably in 24-hour studies of gastric acidity. Dig Dis Sci 1990; 35: 1473-81.

27 Mela GS, Savarino V, Malesci A, Di Mario F, Sossai P, Vigneri S, et al. New method for improving accuracy of 24-hour continuous intragastric pH-metry. Reflections on physiological and pharmacological studies. Dig Dis $\mathrm{Sc}$ 1994; 39: 1416-24.

28 Smith JTL, Pounder RE, Nwokolo CV, Lanzon-Miller S, Evans DG, Graham DY, et al. Inappropriate hypergastrinaemia in asymptomatic healthy subjects infected with Helicobacter pylori. Gut 1990; 31: 522-5.

29 Wagner S, Schüler A, Gebel M, Freise J, Schmidt FW. Campylobacter pylori and acid secretion. Lancet 1989; ii: 562.

30 Bauerfeind P, Cilluffo T, Fimmel CJ, Emde C, V Ritter C, Kohler W, et al. Does smoking interfere with the effect of histamine $\mathrm{H} 2$-receptor antagonists on intragastric acidity in man? Gut 1987; 28: 549-56.

31 Mela GS, Savarino V, Sumberaz A, Bonifacino G, Zentilin P, Villa $\mathrm{G}$, et al. Continuous acidity monitoring in the study of gastric antisecretory drugs: $\mathrm{pH}$ or antilog transformation of $\mathrm{pH}$, mean or median? Am $\mathcal{f}$ Gastroenterol 1990; 85: 1105-8.

32 Mela GS, Savarino V, Vigneri S. Optimizing the information obtained from continuous 24-hour $\mathrm{pH}$ monitoring. Am $\mathcal{f}$ Gastroenterol 1992; 87: 961-6.

33 Patrick WJA, Denham D, Forest APM. Mucosal change in the human duodenum: a light and electron microscopic study and correlation with disease and gastric acid secretion. Gut 1974; 15: 767-76.

34 Kreuning J, Wal AMVD, Kuiper G, Lindeman J. Chronic nonspecific duodenitis. A multiple biopsy study of the nonspecific duodenitis. A multiple biopsy study of the 1989; 24 (suppl 167): 16-20.

35 Yang H, Dixon MF, Zuo J, Fong F, Zhou D, Corthésy I, et al. Helicobacter pylori infection and gastric metaplasia in the duodenum in China. $\mathcal{F}$ Clin Gatroenterol 1995; 20: 110-2.

36 Schulze S, Pedersen NT, Jorgensen MJ, Mollman KM, Rune SJ. Association between duodenal bulb ulceration and reduced exocrine pancreatic function. Gut 1983; 24: 781-3.

37 Rapier RC, Dreilinger AD, Nyberg LM, Koss MA, Hogan DL, Isenberg II. Helicobacter pylori diminishes proximal duodenal musocal bicarbonate secretion in patients with duodenal ulcer disease. Gastroenterology 1994; 106: A164.

38 Bendtsen F, Rosenkilde-Gram B, Tage-Jensen U, Ovesen L Rune SJ. Duodenal bulb acidity in patients with duodenal ulcer. Gastroenterology 1987; 93: 1263-9.

39 Kerrigan DD, Read NW, Taylor ME, Houghton LA, Johnson AG. Duodenal bulb acidity and the natural history of duodenal ulceration. Lancet 1989; ii: 61-3.

40 Jönsson KA, Strom M, Bodemar G, Norrby K. Histologic changes in the gastroduodenal mucosa after long-term medical treatment with cimetidine or parietal cell vagotomy in patients with juxtapyloric ulcer disease. Scand $\mathcal{F}$ Gastroenterol 1988; 23: 433-41.

41 Khulusi S, Mendall MA, Badve S, Patel P, Finlayson C, Northfield TC. Effect of Helicobacter pylori eradication on gastric metaplasia of the duodenum. Gut 1995; 36: on gastric

42 Wyatt JI, Rathbone BJ. Gastric metaplasia in the duodenum and Campylobacter pylori. Gastroenterol Clin Biol 1989; 13: 78-82B.

43 Stockman JM, Young VT, Jenkins AL. Duplication of the rectum containing gastric mucosa. $f A M A 1960 ; 173$ : 1223-5.

44 Wright NA, Pike C, Elia G. Induction of a novel epidermal growth factor-secreting cell lineage by mucosal alteration in human gastrointestinal stem cells. Nature 1990; 343: 82-5.

45 Lev R, Thomas E, Parl FF, Pitchumoni CS. Pathological and histomorphometric study of the effects of alcohol on the human duodenum. Digestion 1980; 20: 207-13. 